\title{
The Effect of General Corrosion on the Guided Wave Inspection of the Pipeline
}

\author{
Jin Heng ZHANG ${ }^{1, a}$, Chang De $\mathrm{LI}^{1, \mathrm{~b}}$, Yang YANG ${ }^{1, c}$ \\ ${ }^{1}$ School of electronics and information, Nanchang Institute of Technology, Nanchang
}

\begin{abstract}
The guided wave method can inspect pipelines very quickly and widely. For instance, it can inspect the overall pipelines by digging several detection pits or removing part of coating material to set the array ring. However, it will make the guided wave attenuate more seriously and make the signals hard to identify when setting the array ring on the general corrosion. In this study, the wave propagation will be discussed when the general corrosion is under the array ring and the severe localized corrosion is inside the general corrosion via experiment and finite element method. The results showed that the excitation energy will be lower when the array ring set on the pipe surface with the general corrosion. By two-dimensional Fourier transform analysis, its non-uniform contact surface will increase asymmetric modal and mix signals. The energy attenuation will increase when the corrosion depth is deepened or the inspection frequency is risen. For example, the $2 \mathrm{~mm}$ deep general corrosion will attenuate $-1.09 \mathrm{~dB} / \mathrm{m}$ at $20 \mathrm{kHz}$ and attenuate $-3.01 \mathrm{~dB} / \mathrm{m}$ at $40 \mathrm{kHz}$; the $4 \mathrm{~mm}$ deep general corrosion will attenuation $-5.76 \mathrm{~dB} / \mathrm{m}$ at $20 \mathrm{kHz}$ and attenuation $-23.19 \mathrm{~dB} / \mathrm{m}$ at $40 \mathrm{kHz}$. However, the coherent signals which were caused by the general corrosion will decay with increasing frequency. For example, the coherent signals of $2 \mathrm{~mm}$ deep general corrosion are $-23.67 \mathrm{~dB}$ at $20 \mathrm{kHz}$ and $-35.44 \mathrm{~dB}$ at 40 $\mathrm{kHz}$; then, the $20 \mathrm{~mm}$ long and $3.5 \mathrm{~mm}$ deep localized corrosion which signal is $-26.34 \mathrm{~dB}$ at $20 \mathrm{kHz}$ and $26.94 \mathrm{~dB}$ at $40 \mathrm{kHz}$ will be detected easily at high frequency. It can provide detectors to understand the impact when the array ring set on the area of general corrosion and the way to distinguish the localized corrosion which is inside the area of general corrosion.
\end{abstract}

Keywords: Guided wave, Finite element method, Two-dimensional Fourier transform, General corrosion, Localized corrosion

\section{Introduction}

In petrochemical plants, the use of pipelines to transport all kinds of fluids are very common. In response to different environmental conditions will be derived from different pipes, such as coated pipelines. Although the pipelines can a hold temperature, fire and stabilization process, but the water vapor will easily penetrate the gap between the clad material and the pipeline. It is easy to form a wide range of general corrosion and possibly mixed with severe localized corrosion, such as Fig 1. And because of the coating material, it will not be easy to perceive the whole pipeline situation, if there have corrosion on the pipeline. In recent years, the guided wave method can inspect pipelines very quickly and widely by digging several detection pits or removing part of coating material to set the array ring.However, it will make the guided wave attenuate more seriously and make the signals hard to identify when setting the array ring on the general corrosion.
For guided wave detection of general corrosion and localized corrosion pipelines. In 2005 ASTM Standard G46 [1] was defined the measurement and evaluation method of corrosion, uniform corrosion on the pipeline and in accordance with the number of holes, the average depth and size of the holes per unit area and made different levels of distinction. In $2009 \mathrm{Su}$, for the research of coating pipelines with general corrosion, to understand the causes of corrosion and its risk parameters and propose different detection methods to prevent it. In 2010, Carandente et al [2] also discuss the relationship between the defect and the defect echo, but for a more detailed appearance defects do research, and found that defects tapered recess which case the reflected signal a trend similar to the defect. In 2011, Løvstad and Cawley [3] pierce hole circumferential distribution and axial distribution of the case, the analysis of the reflection coefficient of torque hole guided wave effects and effective use of the single-hole signal superimposed way to predict the random distribution of holes echo situation.

\footnotetext{
a Corresponding author: 416244710@qq.com
} 
In 2012, Cobb et al [4] conducted research for the uniform corrosion, and they changes temperature, different covering parameters such as attenuation investigate the case, as the determination of the severity of uniform corrosion. In2013 EPRI's test report [5], also pointed out that the general corrosion on the pipeline will cause attenuation of guided wave energy and cause other problems caused by signal enhancement judgment on background signals.

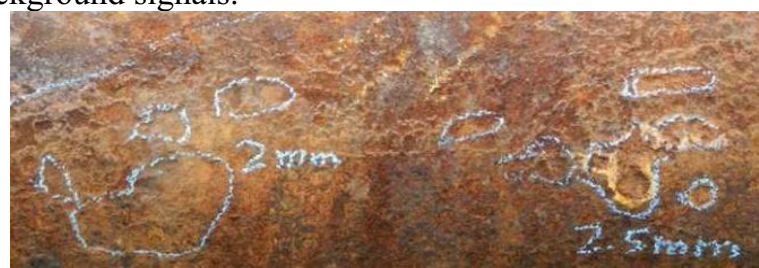

Fig 1 general corrosion with severe localized corrosion

\section{Research approach}

\subsection{Dispersion curve}

Dispersion curves is the relation diagram between group velocities or phase velocities and frequency. As shown in Fig.2, it is the group velocity dispersion curve for a 6-inch pipe, it can see that the used in this research, there is a non-dispersion mode $\mathrm{T}(0,1)$.

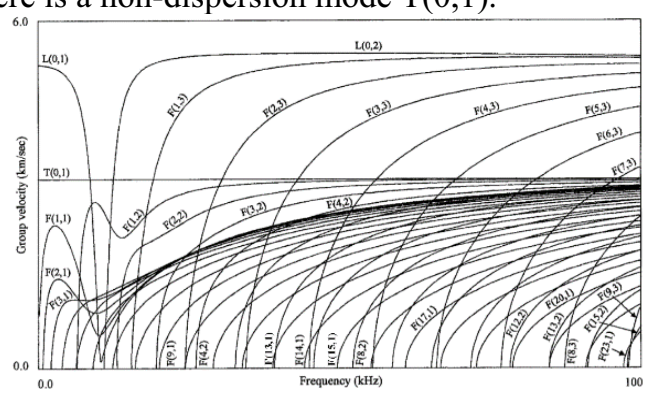

Fig 2 Dispersion curves

\subsection{The Setting of the general corrosion model}

General corrosion is the case of the entire metal surface corrosion on the pipelines and with a consistent average corrosion depth. The simulation will construct numerous round holes to approximate the case of general corrosion when the ratio of the maximum depth and the average depth of the holes is 1 can be expressed as general corrosion. The general corrosion pipeline model will set a single aperture of $15 \mathrm{~mm}$, depth of $1 \mathrm{~mm}$ round hole and construct on different numbers and distribution. The paint must first fraction prior to the construction of the pipeline corrosion, thereby setting coordinates $(\mathrm{X}, \mathrm{Y}), \mathrm{X}$ represents the direction of the longitudinal axis of the pipeline, $\mathrm{Y}$ represents the circumferential location of the pipeline which the circumferential tube every 6 degrees (about $9 \mathrm{~mm}$ arc length)-divided into units, each tube axial $9 \mathrm{~mm}$ divided into a unit.And then, use Matlab software to draw the coordinate points, based on the random nonce selected in the circumferential and axial positions and the coordinate values established hole thereon, as shown in Fig 3.

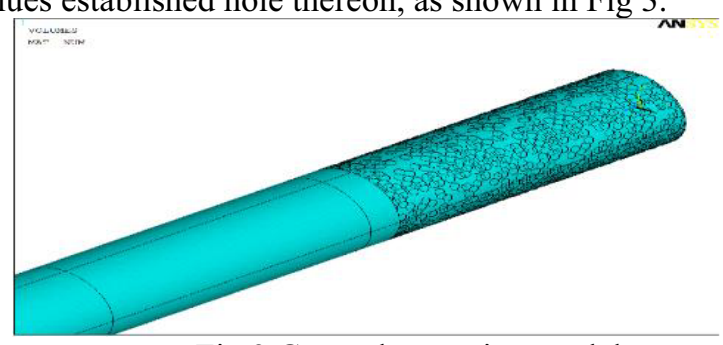

Fig 3 General corrosion model

\subsection{Two-dimensional fourier transform}

After the solution of finite element, the time-domain signal can be retrieved at any point in the structure. Through the two-dimensional fourier transform method can further analyze the relationship between the frequency and wave number, to investigate the wave propagation mode. It isassume the harmonic waves, which propagating along with elastic, homogeneous, and isotropic material, the particle displacement can be expressed as

$$
u(x, t)=A(\omega) e^{i(\omega t-k x-\theta)}
$$

Wherein $x$ is position, $t$ is the time, $A(\omega)$ is the amplitude dependent with frequency, $k$ is the wave number, $\omega$ is the angular frequency, $\theta$ is the phase.The two-dimensional fourier transform method, including a function of time and position, the conversion equation can be expressed as

$$
H(k, f)=\int_{-\infty}^{+\infty} \int_{-\infty}^{+\infty} u(x, t) e^{-i(k x+\omega t)} d x d t
$$

\section{The simulation set and analysis}

\subsection{The simulation of wave propagation}

In this paper, 6-inch steel pipelines were construct which is 3.6 meters long, outer radius of $84 \mathrm{~mm}, 7 \mathrm{~mm}$ thickness and the general corrosion zone is $0.5 \mathrm{~m}$, such as Fig 4.Then construct a distributed evenly full circle tube surface corrosion depth 1,2 and $4 \mathrm{~mm}$ in the model simulations, and using frequency of 20,30 and $40 \mathrm{kHz}$ for testing.Fig 5(a)-(f) can found that the corrosion area is formed of two main echo signal wave packet. The main reflection signals are caused by the edges of corrosion. The corrosion signal will decrease with the increasing frequency. It exhibit that uniform corrosion at high frequencies will have less obvious reflections. When the uniform corrosion depth was $4 \mathrm{~mm}$, it will make more apparent reflection signals because of changing crosssectional area increase and cause greater reflection signals.And the increasing corrosion depth also caused more penetrable and reduce the reflected energy. 
In order to define the extent of corrosion decay, we will measure its incident wave amplitude (I) and the transmission wave amplitude to analysis the attenuation. The result are shown in Fig 6. General corrosion attenuation with $1 \mathrm{~mm}$ and $2 \mathrm{~mm}$ depth does not have much downward trend with the enhanc frequency, but the corrosion depth. However, when etching depth of $4 \mathrm{~mm}$ its attenuated will be significantly decreased. For example, the $2 \mathrm{~mm}$ deep general corrosion will attenuate $-1.09 \mathrm{~dB} / \mathrm{m}$ at $20 \mathrm{kHz}$ and attenuate $-3.01 \mathrm{~dB} / \mathrm{m}$ at $40 \mathrm{kHz}$; the $4 \mathrm{~mm}$ deep general corrosion will attenuation -5.76 $\mathrm{dB} / \mathrm{m}$ at $20 \mathrm{kHz}$ and attenuation $-23.19 \mathrm{~dB} / \mathrm{m}$ at $40 \mathrm{kHz}$.
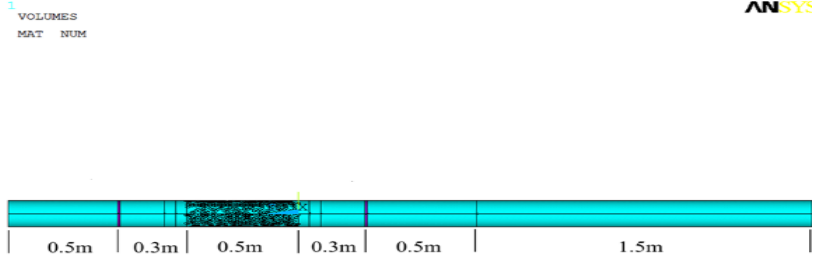

Fig 4 The size and characteristics of the pipeline
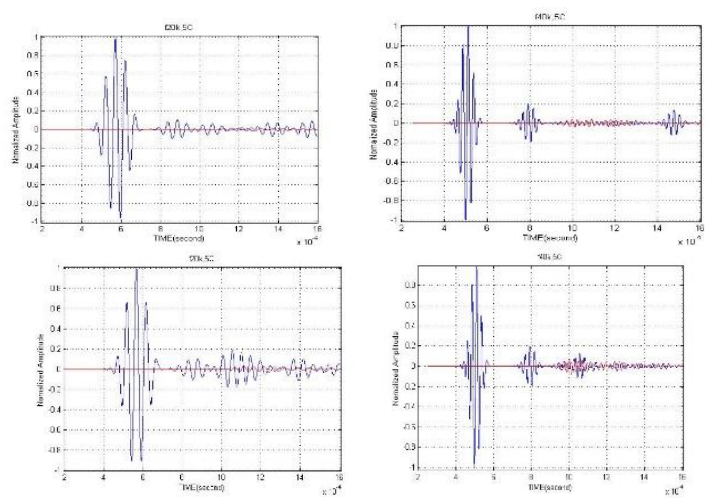

Fig 5 Uniform corrosion depth of $1 \mathrm{~mm}, 2 \mathrm{~mm}$ and $4 \mathrm{~mm}$ of the time domain signal

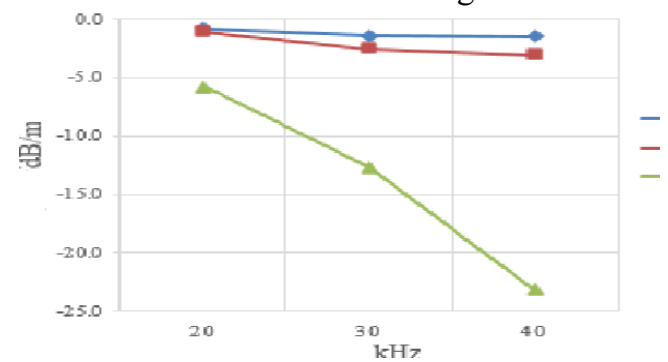

Fig 6 Attenuation of the uniform corrosion

\subsection{Local defects results and discussion}

As stated previously, the same 6-inch steel pipeline was used and constructed a defect at two meters away from the pipe bottom. Then use a center frequency of 20 , 30 and $40 \mathrm{kHz} 5$ cycles of modulation signal to excite the torque mode. First, set a local defects D1 length of 20 $\mathrm{mm}$, and then, set a local defects D2 length of $40 \mathrm{~mm}$, both of the two defects depths are $3.5 \mathrm{~mm}$ and the circumferential are $1 / 10$ distribution perimeter. Using the center frequency of $40 \mathrm{kHz}$, a wavelength of $81.5 \mathrm{~mm}$ of the $\mathrm{T}(0,1)$ guided wave to detect $\mathrm{D} 1$, its $\mathrm{L} / \lambda=0.245$, the reflection coefficient is 0.0635 local defects. At theFrequency of $30 \mathrm{kHz}$, the wavelength of $100.8 \mathrm{~mm}$ of $\mathrm{T}(0,1)$ guided wave testing, its $\mathrm{L} / \lambda=0.184$, partial defect reflection coefficient is 0.0629 ; At theFrequency of $20 \mathrm{kHz}$, the wavelength of $162 \mathrm{~mm}$ of $\mathrm{T}(0,1)$ guided wave testing, its $\mathrm{L} / \lambda=0.123$, partial defect reflection coefficient is 0.0565 ; To detect defect D2, At theFrequency of $40 \mathrm{kHz}$, the wavelength of $81.5 \mathrm{~mm}$ of $\mathrm{T}(0,1)$ guided wave testing, its $\mathrm{L} / \lambda=0.490$, defect reflection coefficient is 0.151 . At theFrequency of $30 \mathrm{kHz}$, the wavelength of $100.8 \mathrm{~mm}$ of $\mathrm{T}(0,1)$ guided wave testing, its $\mathrm{L} / \lambda=0.368$, defect reflection coefficient is 0.0352 . At theFrequency of $20 \mathrm{kHz}$, the wavelength of $162 \mathrm{~mm}$ of $\mathrm{T}(0,1)$ guided wave testing, its $\mathrm{L} / \lambda=0.245$, defect reflection coefficient is 0.0635 . The result are shown in Fig7. The reflection coefficient of local defect D1 will also rise with increasing frequency, and the reflection coefficient of local defect D2 will decrease with increasing frequency.

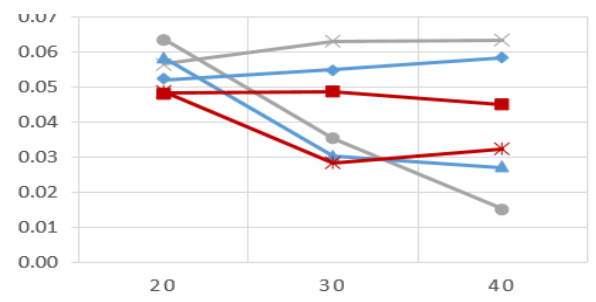

Fig 7 Defects reflection coefficient

\subsection{The discussion of uniform corrosion with localize defects}

In order to understand whether localize defects signals will interfere with the uniform corrosion. It will continued the setting in 3.1 section and added the localized defects D1, D2 in the uniform corrosion. The result are shown in Fig8-9. When the local defects D1 in $1 \mathrm{~mm}$ and $2 \mathrm{~mm}$ uniform corrosion, the increasing frequency will make the localized defects signal more obvious. Because the uniform corrosion signal will decrease with the increasing frequency and the local defects D1 will increase with the increasing frequency. However, the local defects D2 signal will mix with uniform corrosion signal at all frequencies. For example, the coherent signals of $2 \mathrm{~mm}$ deep general corrosion are $23.67 \mathrm{~dB}$ at $20 \mathrm{kHz}$ and $-35.44 \mathrm{~dB}$ at $40 \mathrm{kHz}$; then, the localized corrosion D1 which signal is $-26.34 \mathrm{~dB}$ at 20 $\mathrm{kHz}$ and $-26.94 \mathrm{~dB}$ at $40 \mathrm{kHz}$ will be detected easily at high frequency. It can provide detectors to understand the way to distinguish the localized corrosion which is inside the area of general corrosion. 


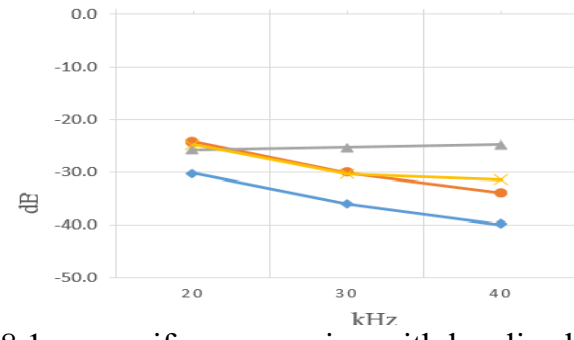

Fig 8 1-mm uniform corrosion with localized defects

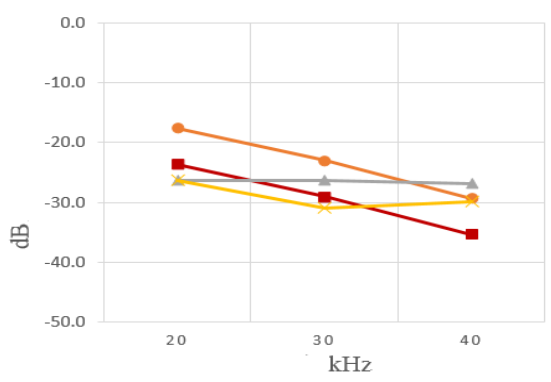

Fig 9 2-mm uniform corrosion with localized defects

\section{$4 \quad$ Experimental measurement results}

\section{setting}

and

\subsection{Instrument}

The experimental measurement instrument is used in the United Kingdom GUL (Guided Ultrasonics Ltd.). The equipment including circular piezoelectric transducers, the signal processor Wavemaker G3 and application software Wave Pro. $\mathrm{T}(0,1)$ is used in the study. The excitation in the frequency regime of 6 inch pipeline is 0.0-3.0, while the operation corresponding to the frequency of $21.39-33.90 \mathrm{kHz}$.

\subsection{Experiment Settings}

In order to understand the results of uniform corrosion detection signal, we use a pipeline with uniform corrosion. The pipeline is 6-inch pipe, radius of $84 \mathrm{~mm}$, thickness $7.1 \mathrm{~mm}$, where the length of uniform corrosion zone is $1.83 \mathrm{~m}$. Next, set the probe on the pipe with clean surface to detect the uniform corrosion. Then, produce two artificial local defects D1 and D2 one after another, such as Fig 10. The defect D1 and D2 depth are all $2.47 \mathrm{~mm}$, perimeter are all $30 \mathrm{~mm}$, axial length are 30 $\mathrm{mm}$ and $60 \mathrm{~mm}$. Finally do the detect again.

\subsection{The results and discussion}

Uniform corrosion signals are clumps of continuous signals, because the actual uniform corrosion area was formed by many corrosion section. Its distribution are not surrounded the full circle of the pipe but on one side of the pipeline. With different corrosion section, it different lengths, and cross-sectional area will vary so the reflected signal will follow the change. By the experiment, it can be found that the D1 signal has a significant value and exceed the measurable limit from low to high frequency. This artificial defects D1 axis length of $30 \mathrm{~mm}$ with a frequency range of the wavelength ratio between 0.18 0.28 . Though the signal was a slight downward at high frequencies, the signals still have more obvious peak as the simulation do and the coherent signals which were caused by the general corrosion will decay with increasing frequency. It will be beneficial to highlight the local defects signal at the high frequency.Then, processing the artificial defects D2 again make it into a $60 \mathrm{~mm}$ shaft and do the same test. This artificial defects D2 axis length of $60 \mathrm{~mm}$ with a frequency range of the wavelength ratio between 0.36-0.56.Comparing with simulation results showed that the signal will be decreased and it can also be seen in the experiment. Such of this defect was easily mixed together with the uniform corrosion at low and high frequency such as Fig 11.

Integration of the above result, the coherent signals which were caused by the general corrosion will decay with increasing frequency, and the local defects signals which was inside the general corrosion will be affect by itself shaft length and the detection frequency.

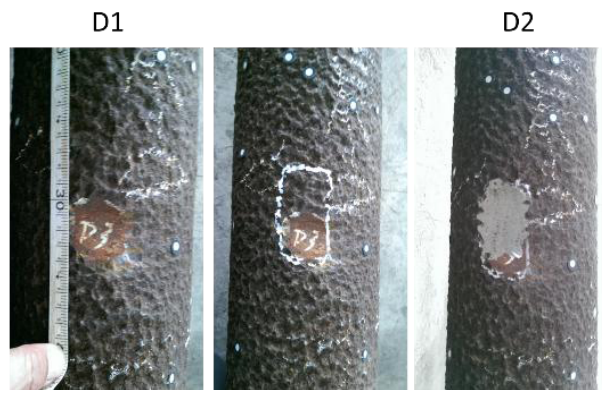

Fig 10 Artificial defects D1 and D2

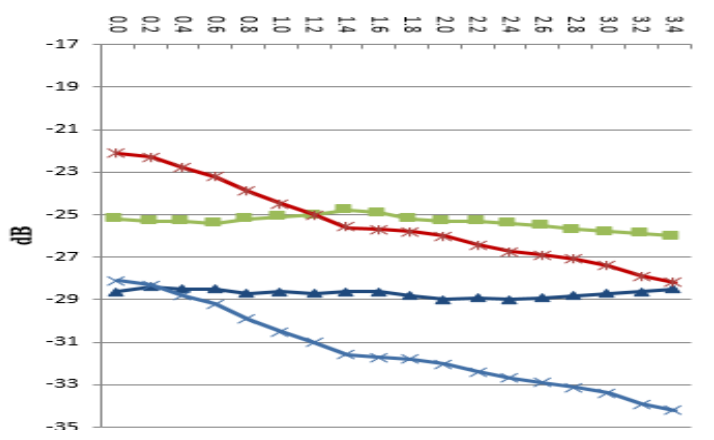

Fig 11 uniform corrosion and local corrosion signal

\section{Conclusions}

The excitation energy will be lower when the array ring set on the pipe surface with the general corrosion. By two-dimensional Fourier transform analysis, its nonuniform contact surface will increase asymmetric modal and mix signals. The energy attenuation will increase when the corrosion depth is deepened or the inspection frequency is risen. For example, the $2 \mathrm{~mm}$ deep general corrosion will attenuate $-1.09 \mathrm{~dB} / \mathrm{m}$ at $20 \mathrm{kHz}$ and attenuate $-3.01 \mathrm{~dB} / \mathrm{m}$ at $40 \mathrm{kHz}$; the $4 \mathrm{~mm}$ deep general corrosion will attenuation $-5.76 \mathrm{~dB} / \mathrm{m}$ at $20 \mathrm{kHz}$ and attenuation $-23.19 \mathrm{~dB} / \mathrm{m}$ at $40 \mathrm{kHz}$. However, the coherent signals which were caused by the general corrosion will decay with increasing frequency. For example, the coherent signals of $2 \mathrm{~mm}$ deep general corrosion are $-23.67 \mathrm{~dB}$ at $20 \mathrm{kHz}$ and $-35.44 \mathrm{~dB}$ at 40 $\mathrm{kHz}$; then, the $20 \mathrm{~mm}$ long and $3.5 \mathrm{~mm}$ deep localized corrosion which signal is $-26.34 \mathrm{~dB}$ at $20 \mathrm{kHz}$ and -26.94 
$\mathrm{dB}$ at $40 \mathrm{kHz}$ will be detected easily at high frequency. It can provide detectors to understand the impact when the array ring set on the area of general corrosion and the way to distinguish the localized corrosion which is inside the area of general corrosion.

\section{References}

1. ASTM Standard G46, "Standard Guide for Examination and Evaluation of Pitting Corrosion," ASTM International, West Conshohocken, PA, 2005.

2. R. Carandente, J. Ma and P. Cawley, "The Scattering of the Fundamental Torsional Mode from Axisymmetric Defects with Varying Depth Profile in Pipes," Journal of the Acoustical Society of America, Vol. 127, pp. 3340-3348, 2010.

3. A. Løvstad and P. Cawley, "The Reflection of the Fundamental Torsional Guided Wave from Multiple Circular Holes in Pipes," NDT\&E International, Vol. 44, pp. 553-562, 2011.

4. A. C. Cobb, H. Kwun, L. Caseres and G. Janega, "Torsional Guided Wave Attenuation in Piping from Coating, Temperature, and Large-area Corrosion," NDT\&E International, Vol. 47, pp. 163-170, 2012.

5. Obtaining Credit for Guided Wave as a Buried Pipe Direct Examination. EPRI, Palo Alto, CA: 2013. 